\title{
KARAKTERISITK SIFAT FISIK TANAH PADA LAHAN PRODUKSI RENDAH DAN TINGGI DI PT GREAT GIANT PINEAPPLE
}

\author{
Holilullah, Afandi \& Hery Novpriansyah \\ Jurusan Agroteknologi, Fakultas Pertanian Universitas Lampung \\ Jl.Prof. Soemantri Brodjonegoro, No.1, Bandar Lampung 35145 \\ E-mail: holilulah@ymail.com
}

\begin{abstract}
ABSTRAK
Sifat fisik tanah merupakan sifat tanah yang berpengaruh terhadap pertumbuhan dan poduksi tanaman karena akan menentukan penetrasi akar di dalam tanah, kemampuan tanah menahan air, drainase, aerasi tanah dan ketersediaan unsur hara tanah. Penelitian ini bertujuan untuk mempelajari dan mengetahui karakteristik sifat fisik yang terdapat pada lahan yang berproduksi rendah dan tinggi. Penelitian dilaksanakan dari bulan Juni sampai September tahun 2013 diPT Great Giant Pineapple (GGP), Lampung Tengah. Penelitian dilakukan dengan menggunakan metode survey dengan menentukan titik sebanyak 6 titik secara diagonal pada lokasi 26 B. Pengambilan sampel tanah dilakukan dengan 2 cara, yaitu mengambil sampel tanah secara langsung dengan menggunakan cangkul dan pengambilan menggunakan ring sampel dengan kedalaman $0-20,20-40$ dan $40-60 \mathrm{~cm}$ serta pada setiap titik dilakukan pembuatan minipit yang bertujuan untuk mengamati profil dan warna tanah. Hasil penelitian menunjukkan bahwa Karakteristik sifat fisik pada lahan produksi rendah memiliki pori drainase sangat rendah sampai dengan sedang, warna tanah coklat kekuningan, tekstur tanah liat berpasir, kekuatan tanah 77,35 psi - 178,89 psi dan kerapatan isi ideal pertumbuhan akar dari kedalaman $0-40 \mathrm{~cm}$ yaitu sebesar $1,36 \mathrm{~g} \mathrm{~cm}^{-3}$ pada kedalaman $0-20 \mathrm{~cm} \mathrm{dan} 1,41 \mathrm{~g} \mathrm{~cm}^{-3}$ pada kedalaman $20-40 \mathrm{~cm}$. Sedangkan Karakteristik sifat fisik pada lahan produksi tinggi memiliki pori drainase sangat rendah sampai dengan sedang, warna tanah orange, tekstur tanah liat berpasir, kekuatan tanah 96,69 psi - 125,70 psi dan kerapatan isi ideal pertumbuhan akar dari kedalaman $0-60 \mathrm{~cm}$ yaitu sebesar $1,29 \mathrm{~g} \mathrm{~cm}^{-3}$ pada kedalaman $0-20 \mathrm{~cm}, 1,38 \mathrm{~g} \mathrm{~cm}^{-3}$ pada kedalaman $20-40 \mathrm{~cm}$ dan $1,45 \mathrm{~g} \mathrm{~cm}^{-3}$ pada kedalaman $40-60 \mathrm{~cm}$.
\end{abstract}

Kata Kunci : aerasi tanah, drainase, kemampuan tanah menahan air, penetrasi akar, profil, unsur hara, susunan pori, warna tanah.

\section{PENDAHULUAN}

Nanas merupakan tanaman buah berupa semak yang mempunyai nama ilmiah Ananas comosus (L) Merr. Tanaman ini berasal dari benua Amerika, tepatnya negara Brazil. Menurut Badan Pusat Statistik (2012), produksi buah nanas di Indonesia pada tahun 2012 sebesar 1.781.899 ton atau naik dari tahun sebelumnya (2011) 1.540.626 ton. Produksi tersebut berasal dari beberaapa daerah di Indonesia, salah satunya Provinsi Lampung yang memiliki produksi buah nanas terbesar di Indonesia pada tahun 2012 sebesar 585.608 ton. Salah satu perusahaan yang memproduksi buah nanas adalah Great Giant Pineapple Company yang memiliki luas total areal sebesar \pm 32.000 hektar dan luas efektif tanaman nanas seluas \pm 20.000 hektar. Jenis tanah pada perkebunan tersebut didominasi oleh tanah Ultisol. Menurut Hardjowigeno (1993) tanah ultisol memiliki kandungan bahan organik yang sangat rendah sehingga memperlihatkan warna tanahnya berwarna merah kekuningan, reaksi tanah yang masam, kejenuhan basa yang rendah, kadar Al yang tinggi, dan tingkat produktivitas yang rendah. Tekstur tanah ini adalah liat hingga liat berpasir, bulk density yang tinggi antara 1,3$1,5 \mathrm{~g} \mathrm{~cm}^{-3}$. Walaupun tanah ultisol sering diidentikkan dengan tanah yang tidak subur, dimana mengandung bahan organik yang rendah, nutrisi rendah dan $\mathrm{pH}$ rendah (kurang dari 5,5) tetapi sesungguhnya bisa dimanfaatkan untuk lahan pertanian potensial jika dilakukan pengelolaan yang memperhatikan kendala yang ada (Munir, 1996).

Tanah ultisol umumnya peka terhadap erosi serta memiliki pori aerasi dan indeks stabilitas rendah sehingga menyebabkan tanah mudah menjadi padat. Akibatnya pertumbuhan akar tanaman terhambat karena daya penetrasi akar ke dalam tanah menjadi berkurang.Salah satu langkah yang dilakukan untuk mengatasi hal tersebut dengan memperbaiki sifat fisik tanah, sifat fisik tanah sangat berpengaruh terhadap kesuburan kimia dan biologi tanah. Oleh sebab itu, upaya perbaikan sifat fisik tanah secara tidak langsung akan memperbaiki sifatsifat kimia dan biologi tanah.

Pemberian bahan organik merupakan salah satu cara untuk memperbaiki sifat fisik tanah. Bahan organik 
dapat memperbaiki struktur tanah, meningkatkan kapasitas menahan air, pori aerasi, dan laju infiltrasi, serta memudahkan penetrasi akar, sehingga produktivitas lahan dan hasil tanaman dapat meningkat (Suwardjo et al. 1984, Anonim 1990). Pemberian bahan organik tidak hanya menghasilkan kondisi fisik tanah yang baik, tetapi juga menyediakan bahan organik hasil pelapukan yang dapat menambah unsur hara bagi tanaman, meningkatkan $\mathrm{pH}$ tanah dan kapasitas tukar kation, menurunkan Aldd, serta meningkatkan aktivitas biologi tanah (Subowo et al. 1990, Sukristiyonubowo et al. 1993).

\section{METODE PENELITIAN}

Penelitian ini dilaksanakan di Perkebunan PT Great Giant Pineapple. Pada penelitian dilaksanakan analisis sifat fisik tanah yang dilakukan di Laboratorium Ilmu Tanah Fakultas Pertanian Universitas Lampung dari bulan Juni sampai September 2013.

Bahan-bahan yang digunakan dalam penelitian ini adalah sampel tanah, air dan larutan calgon $\left(\mathrm{NaPO}_{3}\right)$ n. Alat-alat yang digunakan dalam penelitian ini adalah cangkul, ring sampel, linggis,oven, plastik, penggaris, penetrometer, spidol, plastik, Munsell Soil Color Chart dan alat-alat laboratorium untuk analisis tanah.
Metode yang digunakan pada penelitian ini adalah metode survei. Pada lokasi 26 B yang akan disurvei dilakukan pembuatan minipit dan pengambilan sampel tanah sebanyak enam titik. Masing - masing tiga titik produksi rendah dan tiga titik produksi tinggi dengan kedalaman $0-20,20-40$ dan $40-60 \mathrm{~cm}$. Penentuan titik survey dilakukan dengan diagonal. Variabel yang diamati adalah: susunan pori tanah, warna tanah, kekuatan tanah, kerapatan isi dan tekstur.

\section{HASIL DAN PEMBAHASAN}

Susunan Pori Tanah. Susunan pori tanah terdiri dari pori drainase cepat, pori drainase lambat, pori-pori makro, pori daya menahan air tanah dan ruang pori total.

Pengaruh kedalaman tanah terhadap susunan pori tanah meliputi pori drainase cepat, pori drainase lambat, pori makro, pori daya menahan air dan ruang pori total. Dari Tabel 1,2,3, 4 dan 5 yang merupakan hasil pengamatan dari lahan produksi rendah dan lahan produksi tinggi, dapat dilihat bahwa pada kedalaman tanah $0-20 \mathrm{~cm}$ memiliki nilai susunan pori tertinggi dibandingkan dengan kedalaman 20 - 40 dan 40 - 60 $\mathrm{cm}$.

Hal tersebut dapat terjadi dikarenakan pada kedalaman $0-20 \mathrm{~cm}$ merupakan tanah top soil. Top soil merupakan lapisan tanah atas yang mengandung

Tabel 1. Pori drainase cepat kedalaman $(0-20,20-40,40-60 \mathrm{~cm})$ pada lahan produksi rendah dan lahan produksi tinggi

\begin{tabular}{cccc}
\hline \multirow{2}{*}{ Lokasi } & \multicolumn{3}{c}{ Pori drainase cepat (\%) } \\
\cline { 2 - 4 } & $0-20$ & $20-40$ & $40-60$ \\
\hline \multirow{2}{*}{ LPR } & 9.01 & 6.63 & 5.81 \\
LPT & 10.14 & 7.75 & 6.45 \\
\hline
\end{tabular}

Tabel 2. Pori drainase lambat kedalaman $(0-20,20-40,40-60 \mathrm{~cm})$ pada lahan produksi rendah dan lahan produksi tinggi

\begin{tabular}{cccc}
\hline \multirow{2}{*}{ Lokasi } & \multicolumn{3}{c}{ Pori drainase lambat $(\%)$} \\
\cline { 2 - 4 } & $0-20$ & $20-40$ & $40-60$ \\
\hline LPR & 2.31 & 2.17 & 1.63 \\
LPT & 2.71 & 2.27 & 1.71
\end{tabular}

Tabel 3. Pori - pori makro kedalaman $(0-20,20-40,40-60 \mathrm{~cm})$ pada lahan produksi rendah dan lahan produksi tinggi

\begin{tabular}{cccc}
\hline \multirow{2}{*}{ Lokasi } & \multicolumn{3}{c}{ Pori - pori makro (\%) } \\
\cline { 2 - 4 } & $0-20$ & $20-40$ & $40-60$ \\
\hline LPR & 11.32 & 8.8 & 7.44 \\
LPT & 12.85 & 10.02 & 8.16 \\
\hline
\end{tabular}


Tabel 4. Pori daya menahan air $(0-20,20-40,40-60 \mathrm{~cm})$ pada lahan produksi rendah dan lahan produksi tinggi

\begin{tabular}{cccc}
\hline \multirow{2}{*}{ Lokasi } & \multicolumn{3}{c}{ Pori daya menahan air $(\%)$} \\
\cline { 2 - 4 } & $0-20$ & $20-40$ & $40-60$ \\
\hline LPR & 31.32 & 27.28 & 26.93 \\
LPT & 30.3 & 28.82 & 28.3 \\
\hline
\end{tabular}

Tabel 5. Ruang pori totaltanah kedalaman $(0-20,20-40,40-60 \mathrm{~cm})$ pada lahan produksi rendah dan lahan produksi tinggi

\begin{tabular}{cccc}
\hline \multirow{2}{*}{ Lokasi } & \multicolumn{3}{c}{ Ruang pori total $(\%)$} \\
\cline { 2 - 4 } & $0-20$ & $20-40$ & $40-60$ \\
\hline LPR & 42.63 & 36.07 & 34.38 \\
LPT & 43.15 & 38.84 & 36.46 \\
\hline
\end{tabular}

bahan organik yang lebih tinggi dibandingkan dengan kedalaman lainnya. Dengan tingginya kandungan bahan organik maka akan mempengaruhi ruang pori. Semakin tinggi bahan organik didalam tanah maka akan semakin besar ruang pori tanah. Menurut Hardjowigeno (2003) bahwa porositas tanah dipengaruhi oleh kandungan bahan organik, struktur tanah, dan tekstur tanah. Porositas tanah tinggi kalau bahan organik tinggi. Tanah dengan struktur granuler/remah, mempunyai porositas yang tinggi daripada tanah-tanah dengan struktur massive/pejal. Tanah dengan tekstur pasir banyak mempunyai poripori makro sehingga sulit menahan air.

Warna Tanah. Pengamatan variabel warna tanah pada lahan produksi rendah dan lahan produksi tinggi dapat dilihat pada Tabel 6. Dari Tabel 6 dapat diketahui bahwa warna tanah yang dominan pada lahan produksi rendah adalah warna coklat kekuningan.Warna coklat kekuningan disebabkan karena adanya kandungan bahan organik yang mengalami proses pencucian tanah, sedangkan warna tanah pada lahan produksi tinggi didominasi oleh warna orange. Warna orangedisebabkan karena adanya kandungan mineral geothit di dalam tanah. Adanya perbedaan warna antar lapisan disebabkan oleh kandungan bahan organik dan kandungan mineral yang terdapat didalam tanah.

Hal ini sesuai dengan Eswaran dan Sys (1970), Allen dan Hajek (1989), Schwertmann dan Taylor (1989).Warna tanah dipengaruhi oleh beberapa faktor, antara lain bahan organik yang menyebabkan warna gelap atau hitam, kandungan mineral primer fraksi ringan seperti kuarsa dan plagioklas yang memberikan warna putih keabuan, serta oksida besi seperti goethit dan hematit yang memberikan warna kecoklatan hingga merah. Makin coklat warna tanah umumnya makin tinggi kandungan geothit, dan makin merah warna tanah makin tinggi kandungan hematit. Warna tanah merupakan petunjuk beberapa sifat tanah, karena warna tanah dipengaruhi oleh beberapa faktor yang terdapat dalam tanah tersebut.Menurut Nurhayati (1986) penyebab perbedaan warna permukaan tanah pada umumnya disebabkan oleh perbedaan bahan organik.Makin tinggi

Tabel 6. Hasil pengamatan warna tanah $(0-20,20-40,40-60 \mathrm{~cm})$ pada lahan produksi rendah dan lahan produksi tinggi

\begin{tabular}{cccc}
\hline \multirow{2}{*}{ Lokasi } & \multicolumn{3}{c}{ Warna Tanah } \\
\cline { 2 - 4 } & $0-20 \mathrm{Cm}$ & $20-40 \mathrm{Cm}$ & $40-60 \mathrm{Cm}$ \\
\hline \multirow{2}{*}{ LPR } & 10 YR 5/6 & 2,5 YR 5/8 & 2,5 YR 5/8 \\
& 10 YR 5/3 & 10 YR 5/4 & 10 YR 5/6 \\
& 10 YR 5/4 & 10 YR 5/4 & 2,5 YR 7/8 \\
LPT & 10 YR 6/6 & 10 YR 6/4 & $2,5 \mathrm{Y} 7 / 8$ \\
& $10 Y R$ 6/6 & 10 YR 5/6 & $2,5 \mathrm{Y} \mathrm{7/8}$ \\
\hline
\end{tabular}


kandungan bahan organik, warna tanah makin gelap.Bahan organik member warna kelabu, kelabu tua atau coklat pada tanah kecuali bila bahan dasarnya tertentu seperti oksida dan besi atau penimbunan garam memodifikasi warna.Akan tetapi banyak tanah tropika dengan kandungan oksida (hematit) yang tinggi berwarna merah, bahkan dengan sejumlah besar bahan organik.

Kekuatan Tanah. Pengamatan variabel kekuatan tanah pada lahan produksi rendah dan lahan produksi tinggi dapat dilihat pada Tabel 7. Dari Tabel 7 dapat diketahui bahwa nilai kekuatan tanah kedalaman $0-20 \mathrm{~cm}$ pada lahan produksi rendah memiliki nilai lebih rendah dibandingkan kedalaman $0-20$ cmpada lahan produksi tinggi, sedangkan nilai kekuatan tanah kedalaman 20 $40 \mathrm{~cm}$ pada lahan produksi rendah memiliki nilai lebih tinggi dibandingkan kedalaman $20-40 \mathrm{~cm}$ pada lahan produksi tinggi.

Hal ini terjadi karena adanya perbedaan ukuran ruang pori antar lapisan, bahwa semakin tinggi ruang pori yang terdapat didalam tanah maka akan semakin rendah kekuatan tanah dan sebaliknya apabila ruang pori rendah maka kekuatan tanah akan semakin tinggi. Menurut Darmawijaya (1997) Konsistensi tanah juga mempunyai hubungan dengan tekstur tanah. Tanah pasir biasanya tak lekat, tak liat dan lepas.Sebaliknya tanah lempungberat memiliki konsistensi sangat liat, sangat teguh, dan keras.Faktor-faktor yang mempengaruhi konsistensi tanah adalah kadar air tanah, bahan-bahan penyemen agregat tanah, bahan dan ukuran agregat tanah, tingkat agregasi, dan faktor-faktor penentu struktur tanah (tekstur, macam lempung,dan kadar bahan organik).

Pada lahan produksi rendah maupun lahan produksi tinggi didominasi oleh tanah bertekstur liat berpasir, hal ini bisa dilihat pada Tabel 9. Apabila tanah bertekstur liat berpasir dalam kondisi kering maka kekuatan tanah pada lahan tersebut akan semakin besar dan sebaliknya apabila tanah liat berpasir dalam kondisi basah maka kekuatan tanah akan semakin kecil. Hal ini diakibatkan karena sifat tanah liat pada saat kondisi kering maka tanah liat akan menyusut sehingga tanah menjadi keras dan apabila tanah liat dalam kondisi basah/ lembab maka tanah liat akan mengembang dan bersifat plastis. Menurut Gliessman (2000) Makin tinggi tingkat konsistensi tanah, maka pengolahan pada tanah tersebut akan makin sulit. Sama halnya sebagaimana pengaruh tekstur dan struktur, konsistensi tanah juga memengaruhi perakaran tanaman, infiltrasi, serta tingkat pengolahan tanah. makin tinggi konsistensi suatu tanah, makin terhambat perakaran suatu tanaman dan infiltrasi air, serta makin sulit pengolahan pada tanah.

Kerapatan Isi. Hasil variabel kerapatan isi lahan produksi rendah dan lahan produksi tinggi dapat dilihat pada Tabel 9. Dari Tabel 8 dapat diketahui bahwa pada lahan produksi rendah kedalaman 40-60 cm merupakan kerapatan isi tidak ideal, sedangkan kerapatan isi pada lahan produksi tinggi kedalaman $0-20 \mathrm{~cm}, 20-40 \mathrm{~cm}$ dan $40-60 \mathrm{~cm}$ merupakan kerapatan isi ideal untuk pertumbuhan akar tanaman nanas. Kerapatan isi merupakan salah satu sifat fisik yang mengindikasikan kemampuan akar tanaman dapat menembus tanah.Tanah dengan tekstur tanah pasir memiliki luas permukaan yang lebih kecil daripada tanah dengan tekstur liat. Dilihat dari ukuran partikelnya, partikel pasir lebih besar daripada partikel liat. Sehingga dapat disimpulkan partikel pasir lebih berat daripada partikel liat. (Foth,1978)

Tekstur Tanah. Hasil analisis tekstur pada lahan produksi rendah dan lahan produksi tinggi dapat dilihat pada Tabel 9. Dari Tabel 9 dapat diketahui bahwa lahan produksi rendah maupun tinggi didominasi oleh tekstur liat berpasir. Jika dilihat dari besarnya kandungan pasir yang terdapat pada dua lahan tersebut maka tergolong tinggi dan mengindikasikan bahwa lahan tersebut tidak terjadi genangan air pada saat hujan. Hal ini dikarenakan sifat tanah yang memiliki kandungan pasir yang tinggi memiliki sifat mudah meloloskan air sehingga aerasi baik dan dekomposisi bahan organik cepat.

Tabel 7. Kekuatan tanah $(0-20,20-40 \mathrm{~cm})$ pada lahan produksi rendah dan lahan produksi tinggi

\begin{tabular}{ccc}
\hline \multirow{2}{*}{ Lokasi } & \multicolumn{2}{c}{ Kekuatan tanah } \\
\cline { 2 - 4 } & $0-20$ & $20-40$ \\
\hline LPR & 77,35 & 178,89 \\
LPT & 96,69 & 125,70 \\
\hline
\end{tabular}


Tabel 8. Kerapatan isi tanah $(0-20,20-40,40-60 \mathrm{~cm})$ pada lahan produksi rendah dan lahan produksi tinggi

\begin{tabular}{cccc}
\hline \multirow{2}{*}{ Lokasi } & \multicolumn{3}{c}{ Kerapatan isi $\left(\mathrm{g} \mathrm{cm}^{-3}\right)$} \\
\cline { 2 - 4 } & $0-20$ & $20-40$ & $40-60$ \\
\hline LPR & 1,36 & 1,41 & 1,54 \\
LPT & 1,29 & 1,38 & 1,45 \\
\hline
\end{tabular}

Tabel 9. Hasil analisis tekstur tanah kedalaman $(0-20,20-40,40-60 \mathrm{~cm})$ pada lahan produksi rendah dan lahan produksi tinggi

\begin{tabular}{ccccc}
\hline \multirow{2}{*}{ Lokasi } & \multicolumn{3}{c}{ Fraksi / Partikel Tanah } & \\
\cline { 2 - 4 } & \% Liat & \% Debu & \% Pasir & \\
\hline \multirow{2}{*}{ LPR } & 45,75 & 9,7 & 44,55 & Liat Berpasir \\
& 43,5 & 9,67 & 46,83 & Liat Berpasir \\
& 30,79 & 10,35 & 58,86 & Lempung Liat Berpasir \\
\multirow{2}{*}{ LPT } & 40,99 & 10,31 & 48,7 & Liat Berpasir \\
& 37,13 & 10,38 & 52,49 & Liat Berpasir \\
& 34,81 & 10,31 & 54,88 & Lempung Liat Berpasir \\
\hline
\end{tabular}

\section{KESIMPULAN DAN SARAN}

\section{Kesimpulan}

Dari hasil penelitian dapat disimpulkan bahwa karakteristik sifat fisik pada lahan produksi rendah memiliki pori drainase sangat rendah sampai dengan sedang, warna tanah coklat kekuningan, tekstur tanah liat berpasir, kekuatan tanah 77,35 psi - 178,89 psi dan kerapatan isi ideal pertumbuhan akar dari kedalaman 0 - $40 \mathrm{~cm}$ yaitu sebesar $1,36 \mathrm{~g} \mathrm{~cm}^{-3}$ pada kedalaman 0 $20 \mathrm{~cm}$ dan $1,41 \mathrm{~g} \mathrm{~cm}^{-3}$ pada kedalaman $20-40 \mathrm{~cm}$. Karakteristik sifat fisik pada lahan produksi tinggi memiliki pori drainase sangat rendah sampai dengan sedang, warna tanah orange, tekstur tanah liat berpasir, kekuatan tanah 96,69 psi - 125,70 psi dan kerapatan isi ideal pertumbuhan akar dari kedalaman $0-60 \mathrm{~cm}$ yaitu sebesar $1,29 \mathrm{~g} \mathrm{~cm}^{-3}$ pada kedalaman $0-20 \mathrm{~cm}, 1,38 \mathrm{~g}$ $\mathrm{cm}^{-3}$ pada kedalaman $20-40 \mathrm{~cm}$ dan $1,45 \mathrm{~g} \mathrm{~cm}^{-3}$ pada kedalaman $40-60 \mathrm{~cm}$.

\section{Saran}

Berdasarkan hasil penelitian disarankan agar dilakukan penelitian lanjutan untuk mengetahui pengaruh sifat fisik tanah terhadap pertumbuhan tanaman nanas.

\section{DAFTAR PUSTAKA}

Badan Pusat Statistik. (2012). Statistik Indonesia 2012. Badan Pusat Statistik Republik Indonesia, Jakarta.
Darmawijaya, M. L. 1997. Klasifikasi Tanah. Gadjah Mada University Press, Yogyakarta.

Eswaran, H. and C. Sys. 1970. An evaluation of the free iron in tropical andesitic soils. Pedologie 20:62-65.

Foth, H.D. 1990. Fundamentals of soil science. John Wiley and Sons. New York.

Gliessman,R.S.2000. AGROECOLOGY Ecological Processes in Sustainable Agriculture. CRC Press LLC., Florida.

Hardjowigeno, S. 1993. Klasifikasi Tanah dan Pedogenesis. Akapres. Jakarta.273 Hal.

Hardjowigeno, S. 2003. Ilmu Tanah. Akademika Pressindo. Jakarta.

Munir, M. 1996. Tanah Ultisol - Tanah Ultisol Di Indonesia. Pustaka Jaya. Jakarta.

Subowo, J. Subagja, dan M. Sudjadi. 1990. Pengaruh Bahan Organik terhadap Pencucian Hara Tanah Ultisol Rangkasbitung Jawa Barat. Pemberitaan Penel. Tanah dan Pupuk. 9:26-31.

Suwardjo, H., Sinukaban, N., dan Barus, A. 1984. Masalah erosi dan konservasi tanahdi Daerah Transmigrasi. Prosiding Pertemuan Teknis Peneliti PolaUsahataniMenunjang transmigrasi. Badan Litbang Pertanian. Deptan. Bogor. 